\title{
Os cursos de graduação em Direito e os movimentos sociais na construção de uma cultura de direitos humanos
}

- Los cursos de Derecho y los movimientos sociales en la construcción de una cultura de derechos humanos

- Law undergraduate courses and social movements in the construction of a human rights culture

Ana Cláudia dos Santos Rocha'

Resumo: O presente estudo tem como objeto a necessidade de interação dos movimentos sociais com a universidade, em especial os cursos jurídicos, para efetivação da formação em direitos humanos. O propósito do estudo é analisar: I) o papel da universidade na construção de uma cultura de direitos humanos; II) como a educação em direitos humanos deve ser implementada nos cursos de graduação em Direito; e III) a importância da inter-relação universidade/movimentos sociais para garantir uma verdadeira educação em/ para direitos humanos. Para atingir tais objetivos, adotou-se a pesquisa documental e bibliográfica a partir do levantamento dos marcos legais e das pesquisas científicas sobre a temática, utilizando como referencial teórico autores como Santos, Chauí, Magendzo, Rabinovich-Berkman e Freire. Já a análise dos textos normativos e científicos se deu pela abordagem qualitativa e pelo procedimento de análise de conteúdo.

Palavras-chave: educação em direitos humanos; formação jurídica; movimentos sociais.

1 Doutora em Educação e professora do curso de Direito da Universidade Federal do Mato Grosso do Sul (UFMS). ana.c.rocha@ufms.br 
Resumen: El presente estudio tiene como objeto la necesidad de que los movimientos sociales interactúen con las universidades, en particular los cursos de Derecho, para poner en práctica la educación en derechos humanos. El propósito del estudio es analizar: i) el papel de la universidad en la construcción de una cultura de derechos humanos; ii) cómo debe implementarse la educación en derechos humanos en los cursos de Derecho; y iii) la importancia de la interrelación entre la universidad y los movimientos sociales para garantizar una verdadera educación en/para los derechos humanos. Para lograr estos objetivos, se adoptó la investigación documental y bibliográfica, a partir del relevamiento de los marcos legales y de las investigaciones científicas sobre el tema, utilizando como referencia teórica a autores como Santos, Chauí, Magendzo, Rabinovich-Berkman y Freire. El análisis de los textos normativos y científicos se llevó a cabo mediante un enfoque cualitativo y el procedimiento de análisis de contenido.

Palabras clave: educación en derechos humanos; educación jurídica; movimientos sociales.

\begin{abstract}
The present study has as its object the need of interaction of social movements with the university, especially legal courses, for the effectiveness of education in human rights. The purpose of the study is to analyze: i) the role of the university in the construction of a human rights culture; ii) how human rights education should be implemented in Law undergraduate courses; and iii) the importance of the university/social movements interrelationship to ensure proper education in/for human rights. To achieve these objectives, documental and bibliographic research was adopted, based on the survey of legal frameworks and scientific research on the theme, using as theoretical framework authors such as Santos, Chauí, Magendzo, Rabinovich-Berkman, and Freire. The analysis of the normative and scientific texts was done through a qualitative approach and the content analysis procedure.
\end{abstract}

Keywords: education in human rights; legal education; social movements. 


\section{Introdução}

Em dezembro de 2020, ocorreu de forma virtual, devido à pandemia de covid-19, o Encontro Nacional de Educação em Direitos Humanos: uma rede em construção, tendo, no dia 3, o "Painel sobre Educação em Direitos Humanos: formação de educadores(as) em movimentos sociais" ${ }^{\prime 2}$.

Das exposições e dos debates ensejados pelo painel, desenhou-se a presente pesquisa, que elege como tema a importância das inter-relações entre universidade/movimentos sociais, em especial de docentes e discentes dos cursos de graduação em Direito para construção de uma cultura em direitos humanos.

Esta pesquisa objetiva analisar qual é o papel da universidade para desconstruir a visão de senso comum acerca dos direitos humanos e fomentar seu conhecimento, sua defesa e o respeito a eles. Tem-se ainda como objetivos específicos inventariar os principais marcos normativos que regulamentam a educação em direitos humanos; demonstrar como ela tem sido implementada nos cursos de graduação em Direito; refletir sobre sua implementação de forma disciplinar e interdisciplinar; e enfatizar a importância da inter-relação universidade/movimentos sociais.

Assim, na primeira seção do texto, verifica-se o papel da universidade na construção de uma cultura em direitos humanos; indicam-se os marcos legais que regulamentam essa função social da universidade; propõe-se uma análise crítica da crise pela qual passa a universidade, enquanto instituição, e da necessidade de uma mudança de paradigma para que ela atinja os pressupostos de educar em/para direitos humanos.

Na segunda seção, seguindo a sistemática de apresentação de marcos legais e referenciais teóricos, passa-se à averiguação de como tem sido implementada a educação em direitos humanos na formação do bacharel em Direito.

Por derradeiro, pela compilação das ideias de pesquisadores da temática e da exposição de casos exitosos de ensino-pesquisa-extensão em universidades brasileiras, em especial na Universidade Federal de Mato Grosso do Sul (UFMS), discorre-se sobre a importância da inter-relação universidade/ movimentos sociais nos cursos jurídicos.

Pautado num referencial teórico pós-moderno (BAUMAN; DONSKIS, 2014; SANTOS, 2011, 2013), propõe-se uma reflexão sobre como a universidade tem contribuído para resolução dos retrocessos dos direitos humanos e efetivação de uma formação mais emancipatória, inclusiva, democrática e cidadã.

2 Expositores no painel: Hamilton Harley (IVH-SP), Susana Sacavino (Novamerica-RJ) e Ana Cláudia dos Santos Rocha (UFMS), sob a mediação de Iradj Roberto Eghrari (Ágere). 


\section{O papel da universidade na construção de uma cultura em direitos humanos}

Em conformidade com o disposto no artigo 205 da Constituição Federal, a educação visa ao "[...] pleno desenvolvimento da pessoa, seu preparo para o exercício da cidadania e sua qualificação para o trabalho" (BRASIL, 1988). Preceitua, ainda, no que tange ao ensino superior, a indissociabilidade entre ensino, pesquisa e extensão.

O Plano Nacional de Educação em Direitos Humanos (PNEDH) entende a educação em direitos humanos em todas as modalidades/etapas da educação como instrumento de construção de uma cultura de direitos humanos, com o escopo de formar uma sociedade pautada nos princípios da democracia, da cidadania ativa e da justiça social. No que se refere à educação em direitos humanos no ensino superior, estabelece a necessidade de promover "[...] uma cultura de promoção, proteção, defesa e reparação dos direitos humanos, por meio de ações interdisciplinares, com formas diferentes de relacionar as múltiplas áreas do conhecimento humano com seus saberes e práticas" (BRASIL, 2007).

Por seu turno, a Lei de Diretrizes e Bases da Educação (LDB), Lei n.o 9.934/1996, em seu artigo 43, preceitua as finalidades do ensino superior, das quais, neste estudo, chama-se atenção para o estímulo ao pensamento crítico e ao conhecimento dos problemas do mundo presente, o estabelecimento de uma relação de reciprocidade com a comunidade e o desenvolvimento do entendimento do homem e do meio em que vive (BRASIL, 1996).

Urge, ainda, destacar que o Ministério da Educação e Cultura (MEC) estabelece Diretrizes Curriculares Nacionais (DCNs) para os cursos ofertados pelas instituições de ensino superior em todo território nacional, em atendimento às Diretrizes Nacionais para Educação em Direitos Humanos. Para tanto, determina a obrigatoriedade de inclusão da educação em direitos humanos, de modo transversal, nos Projetos Pedagógicos de Curso (PPC) (BRASIL, 2012, art. $6^{\circ}$ ). Para a organização dos currículos, inserem-se conhecimentos atrelados à educação em direitos humanos, pela transversalidade, como disciplina específica e/ou de maneira mista; opta-se, assim, em combinar transversalidade com disciplinaridade (BRASIL, 2012, art. 70).

Dentre todos os instrumentos normativos elencados, o que se extrai, em comum, é que o ensino superior e o papel da universidade precisam ser (res) significados. A educação superior não deve restringir-se a formação profissional e a ser um centro de excelência de pesquisa científica elitista. Assim, para atingir os objetivos da educação em direitos humanos, a universidade deve primar 
pelo ensino-pesquisa-extensão sob o viés de uma formação mais humanizada e possibilitando inter-relação entre docentes-discentes-sociedade.

Santos (2013) ressalta que a universidade, no século XXI, passa por uma crise paradigmática institucional e de sua hegemonia e legitimidade, sendo necessária uma reforma democrática e emancipatória da universidade para (res) significar sua definição, com o escopo de defendê-la da descapitalização, da transnacionalização e do conhecimento pluriversitário voltado às parcerias universidade-indústria nos moldes neoliberais, que transformam o acesso ao ensino superior em um serviço de consumo, e não uma via da cidadania; convertem estudantes em consumidores, ao invés de cidadãos; e propõem a substituição do paradigma institucional da universidade por um paradigma empresarial.

Atualmente, o que se vislumbra no cenário nacional e internacional é o retrocesso de direitos humanos em decorrência da expansão do neoliberalismo, o que atinge a universidade e resulta na privatização-mercantilização do ensino superior, na colonização da cultura e na adoção de estratégias, cuja ideia geral é "[...] consiga você mesmo o dinheiro, sem ajuda do Estado nem da universidade" (BAUMAN; DONSKIS, 2014, p. 163).

Como alerta Chauí (2003), a universidade como instituição social - concebida como constitutiva de cidadania, democracia e democratização do saber - tem sido alvo de mudanças que a tem descaracterizado. Dentre elas, a educação de um direito passou a ser regulada como um serviço, que pode ser privado ou privatizado, o que resultou na alteração da concepção da universidade como instituição social para organização prestadora de serviços, transformando-a em uma universidade operacional.

Ao se remodelar como universidade operacional, o ensino é pensado como forma de habilitar graduados para o mercado de trabalho, e a pesquisa passa a ser destinada à apropriação privada - já que, fomentada pelo mercado, submete-se às exigências do capital (CHAUÍ, 2003). Esse modelo operacional, a mercantilização do ensino superior e a definição das pautas de ensino-pesquisa-extensão determinadas pelas necessidades do mercado colocam essa instituição social cada vez mais distante de atingir seu escopo ético de educar em/para direitos humanos.

Nesse sentido, ao repensar a universidade, é imperioso que se cogite como o ensino-pesquisa-extensão, em suas práticas interdisciplinares acerca da educação em direitos humanos, tem respondido aos movimentos sociais, à violência e à corrupção. Não basta a educação em direitos humanos estar presente nas universidades - como cursos, cátedras, conferências - sem haver uma postura questionadora, ensinando apenas as normativas; mas sim que ela trabalhe a educação em direitos humanos por um currículo, uma pedagogia e uma didática em uma perspectiva que possibilite o diálogo dos 
estudantes sobre as controvérsias e os dilemas dos direitos humanos, a pesquisa-ação, a inter-relação universidade-sociedade (MAGENDZO, 2017).

Destarte, Kandel (2017) reforça a necessidade de que a universidade se ocupe da formação da cidadania e dos direitos humanos; trabalhe com problemas concretos, grupos reais, com problemas sentidos e existentes onde ela está situada, possibilitando, assim, um processo de (co)produção de conhecimento, de modo que os currículos incorporem a voz de silenciados e invisíveis, abordem dilemas morais, políticos, e que dessa perspectiva da instituição universidade como lócus de construção e do compartilhamento do conhecimento, a educação em direitos humanos seja trabalhada não meramente em seus aspectos normativos e de valores, mas também com enfoque prático, o que resultará numa formação em nível superior integral e humanística.

Para educar em direitos humanos, a universidade precisa romper com a lógica mercantilizada que impôs a ela uma interpretação neoliberal de ensino-pesquisa-extensão, reduzida à investigação, ao ensino e à prestação de serviços, privilegiando o conteúdo utilitarista e produtivista; bem como repensar suas dicotomias alta cultura-cultura popular, educação-trabalho e teoria-prática (SANTOS, 2013).

Ante as crises pelas quais passa a sociedade e consequentemente a universidade, educar em/para os direitos humanos demonstra-se imprescindível, e a universidade, para desempenhar seu papel institucional, tem que abandonar a concepção de que massificação do ensino superior é sinônimo de democratização. Para isso, Chauí (2003) sugere a articulação entre ensino superior público e outros níveis de ensino público; reformar as grades curriculares que produzem a escolarização da universidade; assegurar simultaneamente a universalidade dos conhecimentos e a regionalidade; revalorizar a pesquisa, no sentido de que a relevância social do tema a ser pesquisado não decorra das necessidades do mercado. Neste ponto crucial, o texto da autora dialoga com a presente pesquisa: as parcerias entre a universidade, tanto na pesquisa como na extensão, com os movimentos sociais como caminho para cidadania, pois possibilita a inter-relação sociedade-universidade, em que a sociedade orienta os caminhos da universidade, e a universidade por meio da extensão possibilita o desenvolvimento crítico e reflexivo desses movimentos.

No presente estudo, opta-se por analisar, dentre as diversas formações ofertadas pelas universidades, a forma com que tem se dado a educação em direitos humanos no curso de bacharelado em Direito e sua inter-relação com os movimentos sociais.

\section{O desafio de educar em/para direitos humanos nos cur- sos de graduação em Direito}


Além dos textos normativos citados alhures, a Resolução n. ${ }^{\circ}$ 5, de 17 de dezembro de 2018, ao estabelecer as Diretrizes Curriculares Nacionais dos cursos de graduação em Direito, preceitua no $\S 4^{\circ}$, de seu artigo $2^{\circ}$, que os PPCs devem contemplar as formas de tratamento transversal às temáticas das diretrizes nacionais, dentre elas a educação em direitos humanos. Ainda preceitua a obrigatoriedade de uma sólida formação geral e humanística (art. $3^{\circ}$ ), prioriza a interdisciplinaridade e a articulação dos saberes nas perspectivas formativas geral, técnico-jurídica e prático-profissional (BRASIL, 2018).

Entretanto, para atingir tais objetivos, o ensino jurídico deve romper com o positivismo jurídico de Hans Kelsen, que, em síntese, reduz os fenômenos jurídicos à dimensão normativa, pois limita a formação jurídica à norma posta, sem questionar sua criação, colocando o sistema normativo, como o princípio e o fim de todo sistema (BITTAR, 2005).

Segundo Pereira e Siquelli (2020), desde sua origem - 1827 - os cursos jurídicos no país, majoritariamente, têm adotado práticas de ensino na perspectiva positivo-normativista. Ainda que os instrumentos normativos pós Constituição Federal de 1988, em especial as DCNs dos cursos de graduação em Direito, indiquem a necessidade da formação humanística para cidadania, tendo a educação em direitos humanos como tema transversal, na prática, observa-se que o eixo de formação fundamental tem relevância reduzida, pois predominam nos PPCs os conteúdos do eixo de formação profissional.

Em pesquisa realizada nas Instituições de Ensino Superior (IES) do estado de Alagoas, constatou-se que, embora formalmente em conformidade com as DCNs, os cursos de graduação em Direito do estado, sobre a educação em direitos humanos, apresentam os seguintes dados:

I) quanto à oferta da disciplina Direitos Humanos: $56 \%$ das IES têm a presença de tal disciplina como componente curricular obrigatório, 5\% como componente curricular eletivo/optativo e 39\% não têm a disciplina Direitos Humanos; II) relativo à carga horária da disciplina Direitos Humanos nas IES, observa-se que a instituição que Ihe atribui maior carga horária, dedica-lhe uma proporção de 1,85\% do seu currículo global, havendo IES que não atingem sequer 1\%; III) da carga horária destinada às disciplinas propedêuticas da formação humanística, apenas seis das 18 instituições analisadas apresentaram um percentual igual ou superior a $5 \%$ da carga horária global do currículo (PALMEIRA; PRADO; CORDEIRO, 2020).

O cenário, provavelmente, não é muito distinto nas IES do restante do país. Pereira e Siquelli (2020) indicam que a predominância do positivismo jurídico nas universidades e, consequentemente, o privilégio dos componentes curriculares do eixo formação e prática, decorrem, em parte, das exigências do 
mercado - concursos públicos, exame da Ordem dos Advogados do Brasil -, que reforçam o tecnicismo da formação jurídica e concluem que para propiciar uma formação crítica, reflexiva e emancipatória é preciso romper com o atual processo formativo positivista e com a mercantilização do ensino jurídico.

Santos (2011) assevera que nos cursos jurídicos domina uma cultura normativista, técnico-burocrática, assentada nas ideias de autonomia do direito, na concepção restritiva do direito e na concepção burocrática ou administrativa dos processos. Ela se manifesta pela prioridade dada ao direito civil e penal; à cultura generalista; à desresponsabilização sistêmica; ao privilégio do poder; ao refúgio burocrático que tem aversão a medidas alternativas; ao distanciamento da sociedade e, consequentemente, de sua realidade; e à independência como autossuficiência, que reluta em aceitar a interdisciplinaridade.

As DCNs em vigor preceituam uma formação para a cidadania e para os direitos humanos nos cursos de Direito, com previsão de interdisciplinaridade, metodologias ativas; integração entre teoria e prática; ensino-pesquisa-extensão indissociável; desenvolvimento de postura crítica, reflexiva e da cultura do diálogo; capacidade de trabalhar em grupos, com respeito à diversidade e ao pluralismo cultural, valorizando as práticas de extensão de caráter social e as ações junto à comunidade (BRASIL, 2018).

Contudo, ao primar pela formação positivista, com preponderância dos conteúdos técnicos do eixo de formação profissional e prática, observa-se uma educação verticalizada, nos moldes denominados por Paulo Freire (2005) como educação bancária. Nela, o discente recebe passivamente os conteúdos e o professor adota uma postura de passar o maior número de conteúdo, resultando numa formação medíocre, sem espaço para a crítica, diálogo e criatividade, tão necessários a uma formação humanística e humanizadora.

Ademais, a educação verticalizada/bancária, a formação técnica-normativista e a preocupação em atender às demandas do mercado agravam-se pela expansão das Faculdades de Direito privadas, que centram, em sua maioria, suas atividades apenas no ensino das leis e dos códigos, adotando uma postura hermética no diálogo com os grupos sociais, com outras áreas do saber, e contratando docentes por critérios atrelados à prática profissional, sem nenhuma preparação pedagógica (SANTOS, 2011).

O problema que se apresenta, portanto, é: como propiciar a educação em direitos humanos nos cursos de graduação em Direito e (res)significar o papel da universidade?

Kandel (2017) discorre sobre a necessidade de trabalhar a educação em direitos humanos nas esferas da norma, do conhecimento e da prática. Isto posto extrai-se que há a necessidade de se: I) conhecer quais são os direitos humanos; II) respeitar os direitos humanos e visualizar na prática sua 
aplicação; e III) formar para que se saiba defender esses direitos.

Nessa acepção, Rabinovich-Berkman (2013) reflete sobre a conveniência em se ter direitos humanos como uma matéria específica ou de serem abordados numa perspectiva interdisciplinar. Se por um lado, eleger direitos humanos como uma disciplina nos currículos das universidades facilitou a difusão desses direitos e sua tomada de consciência, por outro, instalou-se uma visão compartimentada dos direitos humanos, desconexa da realidade e, muitas vezes, reduzida ao estudo das normas.

Salienta Rabinovich-Berkman (2013) que há uma conveniência pedagógica em ensinar e expor os direitos humanos como uma matéria essencial nos planos das carreiras jurídicas, mas o assunto possui aspectos técnicos complexos, que necessitam do câmbio e da integração entre diferentes áreas científicas para construir conjuntamente os conceitos de humanidade, pessoa e dignidade humana.

Sendo assim, o ensino dos direitos humanos pode ser (e é interessante que seja) incluído como um componente curricular nos cursos de Direito, mas ele também deve se dar numa perspectiva interdisciplinar, para não incorrer no perigo da especialização, que, metaforicamente, é comparado por Rabinovich-Berkman (2013) ao fato de que se o estudioso se concentra demasiadamente no estudo da árvore, não perceberá as características do bosque.

Destarte, o desafio de educar em direitos humanos no curso de Direito requer que os direitos humanos, para além de uma oferta como componente curricular, permeiem os estudos de todas as disciplinas do eixo de formação geral, técnico-jurídica e prático-profissional.

Para Santos (2011), a formação jurídica no Brasil só adotará um modelo educacional socialmente comprometido e epistemologicamente mais sofisticado se se assentar numa ecologia dos saberes jurídicos. Elucida o autor que não é mais concebível continuar a ensinar, por exemplo, o direito de propriedade apenas na visão individualista do Código Civil. A transversalidade dos direitos humanos implica aulas de direito - de todos os componentes curriculares - que dialoguem com o conhecimento jurídico popular e científico e com as múltiplas vozes: dos professores, dos alunos e de integrantes dos mais variados movimentos sociais e organizações sociais.

Nesse ínterim, a formação em/para direitos humanos nos cursos de graduação de Direito exige a indissociabilidade entre ensino-pesquisa-extensão, pautada em pesquisa-ação e inter-relação dos graduandos com os movimentos sociais.

\section{A necessária inter-relação entre os graduandos em Di- reito e os movimentos sociais}

De todo o apresentado até o momento, é indubitável que uma verda- 
deira e significativa educação em direitos humanos nas graduações de Direito demanda uma formação que possibilite ao aluno o conhecimento das normas, a sua aplicação nos casos concretos, os modos de defender tais direitos, bem como uma abordagem de maneira disciplinar e interdisciplinar, que integre ensino-pesquisa-extensão e a teoria-prática.

Dentre as experiências exitosas na construção desse novo sentido da formação jurídica, a inter-relação docentes/discentes/movimentos sociais tem ocupado lugar de destaque. Nesse sentido, Santos (2011) cita como exemplos os projetos "Polos da Cidadania", da Universidade Federal de Minas Gerais (UFMG), e "O Direito Achado na Rua", da Universidade de Brasília (UnB).

Por sua vez, Camargo e Flumian (2012) discorrem sobre a experiência resultante de um Projeto de Ensino desenvolvido na Universidade Federal de Mato Grosso do Sul (UFMS), campus de Três Lagoas, intitulado "Primeiro dia na advocacia: a educação em Direitos Humanos dentro e fora das salas de aula". No projeto, oportunizava-se a interação e o diálogo entre os alunos; e o debate por meio de audiências simuladas que envolviam problemas concretos, de grupos reais, dilemas morais e políticos de difícil resolução, sobre temáticas atinentes à violência doméstica (Lei n. ${ }^{0} 11.340 / 06$ - Lei Maria da Penha), ao Estatuto do Idoso (Lei n. ${ }^{\circ} 10.741 / 03$ ), ao Estatuto da Igualdade Racial (Lei n. $\left.{ }^{\circ} 12.288 / 2010\right)$, à Lei de Alienação Parental (Lei n. $\left.{ }^{\circ} 12.318 / 2010\right)$ e à Lei de Alimentos Gravídicos (Lei n. ${ }^{0} 11.804 / 08$ ).

Já Genuino, Martins e Nomizo (2012) ressaltam a importância dos Núcleos de Práticas Jurídicas na proteção e na promoção dos direitos humanos e da cidadania, posto que nos atendimentos feitos em tais núcleos, possibilita-se aos alunos o contato com as demandas da sociedade, onde a universidade está inserida e enseja uma formação mais humanística, servindo, nesse contexto, de ferramenta de aproximação do estudante com a realidade social e a garantia do acesso à justiça aos hipossuficientes e vulneráveis.

Nesse segmento, Carvalho (2003), em sua dissertação, discorre sobre o projeto-piloto da Universidade Federal da Bahia (UFBA) - Atividade Curricular em Comunidade (ACC) - como exemplo de extensão universitária que propicia a inter-relação entre universidade pública e demandas sociais, destacando a ACC: "Ações Interdisciplinares em Áreas de Reforma Agrária EDC 456".

Das experiências elencadas, o que se percebe é a análise crítica dos direitos humanos por meio da dicotomia inclusão-exclusão. Ao possibilitar a inter-relação universidade/movimentos sociais, o processo ensino-aprendizagem dos direitos humanos propõe a reflexão sobre questões sociais que têm fomentado discursos de culpabilização da pobreza, de intolerância com as minorias e de ataques aos direitos humanos, agravados pela diminuição do Estado (VALENÇA; PAIVA, 2014). 
A inter-relação entre docentes/discentes/movimentos sociais e discursos e práticas em direitos humanos enseja a reflexão do "outro", como "não eu"; a formação de educadores formais e informais, de líderes comunitários e de pessoas empenhadas na defesa da dignidade. Implica também construir um novo modelo educacional voltado à emancipação e à resistência, pois proporciona conhecer, defender e respeitar a igualdade de direitos dos outros, a comunicação de saberes, de valores, e o empoderamento desses "outros". (DURAN; DURAN, 2014)

Adaptando o pensamento de Boaventura de Sousa Santos (2013) acerca da universidade pautada pela ciência moderna nos cursos jurídicos, pode-se afirmar que para uma verdadeira educação em direitos humanos é preciso transformar os processos de investigação, ensino e extensão; promover discussões transdisciplinares; privilegiar a intervenção social, humanística, artística e literária e a presença de ativistas sociais, das classes sociais oprimidas e dos grupos socialmente discriminados.

Nesse contexto, com o intuito de demonstrar os caminhos percorridos pelo campus de Três Lagoas da Universidade Federal de Mato Grosso do Sul (UFMS), destacam-se alguns projetos atualmente em curso que têm primado por essa inter-relação tão necessária à formação em/para direitos humanos: - A "Universidade Aberta para os Idosos", denominada UMI (Universidade da Melhor Idade) ${ }^{3}$ possibilita aos alunos não apenas do Direito, mas de todos os cursos do campus, a um só tempo ensino-pesquisa-extensão, pela transdisciplinaridade ao atuarem nesse projeto, que visa incluir social, educacional e tecnologicamente a pessoa idosa.

- O projeto de extensão "Universidade Necessária"4 objetiva articular ensino e pesquisa e as demandas da sociedade, estimular o senso crítico, a atuação profissional pautada na cidadania e na função social da educação superior, integrando o saber acadêmico e o saber popular. Tal projeto oferta as seguintes atividades: café com política; biblioteca colaborativa e feira de livros do pensamento crítico; atividades de formação; núcleo de auditoria cidadã da dívida; apoio e organizações de demandas sociais.

- Núcleo de Mediação e Conciliação do Escritório Modelo de Assistência Jurídica da UFMS 5 , implementado pelo professor Me. Evandro Carlos Garcia e coorde-

3 Projeto de extensão, coordenado pela professora Dra. Vanessa Cristina Lourenço Casotti Ferreira da Palma, do curso de Direito, desde 2011.

4 Projeto, coordenado pela técnica Gleice Carlos Nogueira Rodrigues, que tem como público-alvo professores da educação básica pública, associações - como a Associação dos Geógrafos Brasileiros (AGB) e Associação Nacional de História (Anpuh) -, sindicatos e comunidade em geral.

5 Núcleo implementado pelo professor Me. Evandro Carlos Garcia e coordenado pela professora Dra. Carolina Ellwanger. 
nado pela professora Dra. Carolina Ellwanger, é um exemplo de formação prática voltada aos meios adequados de solução de conflitos e da cultura de paz. - O projeto de pesquisa “Educação em Direitos Humanos: fundamentos, políticas e práticas ${ }^{16}$ promove pesquisas, encontros e eventos pautados na tríplice análise: I) fundamentos: legislação pátria, tratados e convenções internacionais acerca da temática; II) políticas públicas implementadas no Brasil para efetivação da educação em direitos humanos; e III) prática: eficácia, eficiência e efetividade dessas políticas públicas.

- O grupo de pesquisa "Direito Agrário e práxis: diálogos transdisciplinares" (UFMS/CNPq) ${ }^{7}$ trata da construção de uma rede de diálogos transdisciplinares sobre temas específicos de Direito Agrário, sob uma perspectiva latino-americana. Fundamenta-se numa concepção histórica-materialista-dialética, pautada na revisão teórica, com vistas à construção de diálogos com pesquisadores do Direito e fora dele, bem como com vários saberes locais originários dos sujeitos de pesquisa, sob um formato de pesquisa-participante.

Todas essas ações de ensino-pesquisa-extensão relatadas, tanto no âmbito da UFMS, campus de Três Lagoas, como dos já consolidados e renomados "O Direito Achado na Rua" (UnB) e"Polos da Cidadania" (UFMG), têm em comum a construção de uma nova formação jurídica, de caráter mais crítico, exploratório e propositivo. Propiciam, assim, uma formação jurídica intercultural, interdisciplinar e voltada à responsabilidade cidadã, como preceituado por Boaventura de Sousa Santos (2011). Como salientam Valença e Paiva (2014, p. 283), os direitos humanos "[...] se revelam e se constroem nas lutas de grupos, partidos e movimentos sociais pela superação de desigualdades e relações de poder".

A universidade e em especial os cursos de graduação em Direito precisam oferecer ensino, pesquisa e extensão articulados com a realidade e romper com as barreiras que limitam sua atuação aos muros das instituições. É necessário sair dos gabinetes, das salas de aula e relacionar-se com a sociedade. É urgente, ainda, que se garanta espaço aos movimentos sociais dentro da universidade. Essa inter-relação é que proporcionará uma verdadeira e sólida formação em/para direitos humanos.

\section{Considerações finais}

A presente pesquisa não tem o escopo de exaurir a temática, nem tampouco de apresentar uma resposta, mas sim de promover a reflexão e suscitar

\footnotetext{
6 Projeto de pesquisa, coordenado pela professora Dra. Ana Cláudia dos Santos Rocha, conta com a participação de pesquisadores, docentes e discentes de diferentes cursos e IES.

7 Grupo de Pesquisa coordenado pelo professor Dr. Cláudio Ribeiro Lopes e pela egressa Juliana Adono da Silva.
} 
o debate sobre a educação em direitos humanos nos cursos de graduação em Direito e o papel da universidade. Da análise dos documentos e da bibliografia levantada, observa-se que garantir a formação em/para direitos humanos e (res)significar o papel da universidade são elementos inseparáveis.

Assim, é necessário que os PPCs de todos os cursos de graduação e pós-graduação, conforme preceituado nos textos normativos, tenham como eixo central a educação em direitos humanos, de forma disciplinar e interdisciplinar.

Essa disciplinaridade e interdisciplinaridade precisam possibilitar aos discentes: o conhecimento dos direitos humanos, enquanto norma, e sua construção histórica; a capacidade de visualizar na prática a aplicação desses direitos; e, ainda, formação para que saibam como defender tais direitos.

Para atingir tal propósito, apresenta-se como caminho a inter-relação universidade/sociedade pela integração e por diálogos entre docentes-discentes-movimentos sociais e organizações sociais. Preceitua-se que a universidade estabeleça pontes com agências governamentais, com organismos não governamentais, com os excluídos, os marginalizados, as minorias e os silenciados. É urgente que a universidade firme um compromisso de educar em/para os direitos humanos ante os retrocessos que se presenciam hodiernamente nessa seara e reconheça a educação como forma de poder.

[...] a educação é o maior dos poderes humanos. Na realidade, se o poder político é o poder-quadro do exercício de todos os outros, na base da pirâmide social das relações de poder está o poder pedagógico. Todos os governantes tiveram uma educação. A educação é o mais natural, acessível, generalizado e difuso dos poderes [...]. A escola tornou-se um operador da legitimação ideológica do poder político, da preparação cultural e técnica para o exercício de outros poderes, da reprodução psicológica e social das relações de poder. O saber tornou-se mesmo, em larga medida, fruto do poder [...] (MONTEIRO, 2015, p. 139).

A universidade precisa se posicionar contrariamente à mercantilização do ensino superior, primar pela integração de saberes, abrir-se para o diálogo com os movimentos sociais. É necessário que o conhecimento científico saia dos gabinetes, das salas de aula e dos muros físicos e imaginários, mas não em forma de extensão voltada aos interesses do mercado ou dos patrocinadores de pesquisa. Enfim, como explanado por Santos (2013), a universidade deve passar por uma reforma democrática e emancipatória.

Em especial, no que tange aos cursos de graduação em Direito, os discentes devem ater-se não apenas nos textos normativos e no posicionamento jurisprudencial dos temas que compõem a grade curricular do curso; é preciso proporcionar uma formação humanista integradora. Para tanto, as atividades de ensino-pesquisa-extensão que possibilitem a inter-relação com os movimentos sociais são, indubitavelmente, uma opção salutar. 


\section{Referências}

BAUMAN, Zygmunt; DONSKIS, Leônidas. Cegueira moral: a perda da sensibilidade na modernidade líquida. 1. ed. Rio de Janeiro, RJ: Zahar, 2014.

BITTAR, Eduardo Carlos Bianca. Curso de filosofia do direito. 4. ed. São Paulo, SP: Atlas, 2005.

BRASIL. Constituição da República Federativa do Brasil de 1988. Brasília, DF: Presidência da República, [2016]. Disponível em: http://www.planalto.gov.br/ ccivil_03/Constituicao/Constituiçao.htm. Acesso em: 19 mai. 2021.

BRASIL. Lei n. 9 9394, de 20 de dezembro de 1996. Estabelece as diretrizes e bases da educação nacional. Brasília, DF: Presidência da República, 1996. Disponível em: http://www.planalto.gov.br/ccivil_03/leis/19394.htm. Acesso em: 19 mai. 2021.

BRASIL.Plano Nacional deEducaçãoem Direitos Humanos. Brasília, DF:Secretaria Especial dos Direitos Humanos: Ministério da Educação: Ministério da Justiça: Unesco, 2007. Disponível em: http://portal.mec.gov.br/docman/2191-planonacional-pdf/file. Acesso em: 19 mai.2021.

BRASIL. Resolução n. ${ }^{1}$, de 30 de maio de 2012. Diretrizes Nacionais para a Educação em Direitos Humanos. Brasília, DF: MEC, 2012. Disponível em: http:// portal.mec.gov.br/dmdocuments/rcp001_12.pdf. Acesso em: 19 mai. 2021.

BRASIL. Resolução n. 5, de 17 de dezembro de 2018. Institui as Diretrizes Curriculares Nacionais do Curso de Graduação em Direito e dá outras providências. Brasília, DF: MEC, 2018. Disponível em: https://www.in.gov.br/ materia/-/asset_publisher/Kujrw0TZC2Mb/content/id/55640393/do1-201812-18-resolucao-n-5-de-17-de-dezembro-de-2018-55640113. Acesso em: 19 mai. 2021.

CAMARGO, Caroline Leite de; FLUMIAN, Michel Ernesto. Educação em Direitos Humanos: relato de uma experiência com projeto de ensino no curso de direito da UFMS, Três Lagoas. In: NOZU, Washington Cesar Shoiti; GENTIL, Plínio Antônio Britto (org.). Educação, direitos humanos e cidadania. Campo Grande, MS: Ed. UFMS, 2012. p. 43-60.

CARVALHO, Marize Souza. Formação de professorese demandas dos movimentos sociais: a universidade necessária. 2003. Dissertação (Mestrado em Educação) 
- Universidade Federal da Bahia, Salvador, 2003.

CHAUÍ, Marilena. A universidade pública sob nova perspectiva. Revista Brasileira de Educação, Rio de Janeiro, n. 24, p. 4-15, set./dez. 2003.

DURAN, Angela Aparecida da Cruz; DURAN, Maria Raquel da Cruz. Pensar o "outro" entre o discurso e a prática dos direitos humanos: contribuições das ciências sociais e jurídicas. In: NOZU, Washington Cesar Shoiti; LONGO, Marcelo Pereira; BRUNO, Marilda Moraes Garcia (org.). Direitos Humanos e inclusão: discursos e práticas sociais. Campo Grande, MS: Ed. UFMS, 2014. p. 287-302.

FREIRE, Paulo. Pedagogia do oprimido. 42. ed. Rio de Janeiro, RJ: Paz e Terra, 2005.

GENUINO, Adejunior; MARTINS, Lisandra Moreira; NOMIZO, Sílvia Leiko. A humanização do ensino jurídico: a atuação dos Núcleos de Prática Jurídica como meio de efetivação dos Direitos Humanos e da Cidadania. In: NOZU, W. C. S.; GENTIL, P. A. B. (org.). Educação, direitos humanos e cidadania. 1 ed. Campo Grande, MS: Editora UFMS, 2012. p. 129-147.

KANDEL, Victória. Experiencias y metodologias para la EDH. In: KANDEL, Victória (comp.). Educación en derechos humanos en América Latina: construyendo perspectivas y trayectoria. 1. ed. Remedios de Escalada, AR: De la UNLa, 2017. p. 57-61.

MAGENDZO, Abraham. Conversando em torno a la educación em derechos humanos desde una mirada controversial y dilemática. In: KANDEL, Victória (comp.). Educación en derechos humanos en América Latina: construyendo perspectivas y trayectoria. 1. ed. Remedios de Escalada, AR: De la UNLa, 2017. p. 33-38.

MONTEIRO, A. Reis. Profissão docente: profissionalidade e autorregulação. São Paulo: Cortez, 2015.

PALMEIRA, Lana Lisiêr de Lima; PRADO, Edna Cristina do; CORDEIRO, Carla Priscilla Barbosa Santos. A educação em Direitos Humanos nos currículos dos cursos de Direito do Estado de Alagoas: um estudo de caso em um caso a ser repensado. Revista Teias, Rio de Janeiro, v. 21, n. 63, p. 392-409, out./dez. 2020. Disponível em: https://www.e-publicacoes.uerj.br/index.php/revistateias/ article/view/49496/36158. Acesso em: 19 mai. 2021. 
PEREIRA, Ricardo Morais; SIQUELLI, Sônia Aparecida. Do positivismo ao positivismo jurídico: reverberações na formação do Bacharel em Direito. Revista Eletrônica de Educação, São Carlos, v. 14, p. 1-12, jan./dez. 2020. Disponível em: http://www.reveduc.ufscar.br/index.php/reveduc/article/ view/2550. Acesso em: 19 mai. 2021.

RABINOVICH-BERKMAN, Ricardo David. ¿Cómo se hicieron los derechos humanos?: un viaje por la historia de los principales derechos de las personas. 1. ed. Buenos Aires, AR: Didot, 2013.

SANTOS, Boaventura de Sousa. Para uma revolução democrática da justiça. 3. ed. São Paulo, SP: Cortez, 2011.

SANTOS, Boaventura de Sousa. Pela mão de Alice: O social e o político na pósmodernidade. 14. ed. São Paulo, SP: Cortez, 2013.

VALENÇA, Daniel Araújo; PAIVA, Ilana Lemos. Direitos humanos: da idealização à materialidade. In: NOZU, W. C. S.; LONGO, M. P.; BRUNO, M. M. G (org.). Direitos Humanos e inclusão: discursos e práticas sociais. Campo Grande, MS: Ed. UFMS, 2014. p. 273-286. 